\title{
Ramadan fasting and diabetes, latest evidence and technological advancements: 2021 update
}

\author{
Ali Tootee ${ }^{1} \cdot$ Bagher Larijan $^{2} \odot$
}

Received: 21 April 2021 / Accepted: 23 April 2021 / Published online: 2 May 2021

(c) Springer Nature Switzerland AG 2021

\begin{abstract}
Development of updated guidelines for management of diabetes in Ramadan Fasting is of paramount importance. Nonetheless, evidence-based guidelines in the field of Ramadan Fasting and Diabetes are scarce. Moreover, findings of some recent research such as effects of Ramadan fasting on microbiota, genetics and epigenetics, hormonal changes (such as adiponectin, leptin, testosterone...), and alternations in circadian rhythm should also be reviewed and included on a yearly basis. It is documented that self-monitoring of blood glucose (SMBG) is of vital importance for patients with type 1 diabetes who fast, and advantages of continuous glucose monitoring (CGM) or flash glucose monitoring (FGM) techniques should be highlighted. Moreover, the recent findings about applications of advanced insulin delivery technology in patients with diabetes who fast in Ramadan should also considered in the annual updates of the guidelines.
\end{abstract}

Keywords Ramadan Fasting $\cdot$ Fasting $\cdot$ Diabetes

\section{Introduction}

In 2019, globally, approximately, 460 million people were living with diabetes, and this number is forecast to increase to 700 million in 2045, a rise of no less than 51\%. [1] On the other hand, by 2045, the number of patients living with diabetes is predicted to increase at least twofold in the Islamic World where a great proportion of the population fast. [2] Therefore, it is imperative that related literature and guidelines on the subject of Ramadan Fasting and diabetes should be updated on a regular basis.

As diabetes is a metabolic disease which involves multiple organs, diabetic patient are at a high risk for development of a wide range of potential fasting-related complications such as dehydration, hypoglycemia, hyperglycemia, and diabetic ketoacidosis (DKA). It should not be overlooked, however, that fasting can be quite beneficial for certain diabetic

Bagher Larijan

emrc@tums.ac.ir

1 Diabetes Research Center, Endocrinology and Metabolism Clinical Sciences Institute, Tehran University of Medical Sciences, Tehran, Iran

2 Endocrinology and Metabolism Research Center, Endocrinology and Metabolism Clinical Sciences Institute, Tehran University of Medical Sciences, Tehran, Iran patients provided that they strictly adhere to the evidencebased guideline and pious physicians' advice [3].

People with diabetes are generally confronted with serious risks such as hypoglycemia and hyperglycemia. Notwithstanding all such risks, many still choose to fast, even those for whom fasting is religiously prohibited. For instance, It is documented that adults with T1DM have a pronouncedly higher incidence of severe hypoglycemia and diabetic ketoacidosis (DKA) if they fast during Ramadan. [4] Nonetheless, many patients with the disease choose to fast every year. Therefore, it is imperative that safe Ramadan Fasting instruction for patients with different types of diabetes should be developed so that the risks involved can be minimized, and this group of diabetic patients can fast in a reasonably safer manner. The major aim of this commentary is to review and update the existing knowledge in the field of Ramadan Fasting for clinicians whose guidance is sought by Muslim patients with diabetes all across the world.

\section{Diabetes education and ramadan fasting}

In all patients with diabetes, Ramadan-focused education is of paramount importance for heightening their awareness of the possible associated risks, and formulation of effective strategies to minimize them. High-risk individuals 
who choose to fast should have access to ample education and support so that the potential risks, particularly those of hyper- and hypoglycemia can be minimized. It should be emphasized that in all educational programs, optimal blood glucose monitoring should be considered as the principal consideration for minimization of the risk of complications [5].

Lifestyle modification can be considered as another key component of Ramadan Fasting education in individuals with diabetes. The fasting-feeding nature of the ritual can predispose diabetic patients to hypoglycemia during the day and hyperglycemia after iftar at night. [6] In most Islamic cultures, consumption of high-calory, high-fat, and carbohydrate-rich meals, confectionaries, and beverages is commonplace in Ramadan, which can adversely affect blood glucose levels and increase the risk of development of hyperglycemia and related complications. [7] This should be strongly discouraged in all educational programs. Moreover, due to the high risk of hypoglycemia and dehydration, patients with diabetes should be prohibited from strenuous exercise, particularly late in the evening and before iftar. [6] Patients should also be informed that consumption of large amounts of high glycemic index (GI) carbohydrates [8] and alternations in physical activity and sleeping patterns can lead to weight gain during Ramadan. [9] Symptoms of hypoglycemia and hyperglycemia should be clearly explained to diabetic patients, and they need to be thought to measure their blood sugar and immediately discontinue fasting if they develop. [10] They also need to be advised that, in case of hypoglycemia, a small amount of a fast-acting carbohydrate (a glass of fruit juice) should be consumed, and they need to retest their blood glucose levels again after $20 \mathrm{~min}$. [11] When there is little opportunity for face-to-face, such as the current Covid-19 pandemic, communication technology and mobile phones should be utilized, which are demonstrated to be effective tools for diabetes education.

\section{Management of patients with type 1 diabetes}

During Ramadan Fasting, proper use of specific insulin types and regimens, and vigilant blood sugar monitoring can be of life-saving importance in minimization of the risk of hypoglycemia. In a recent global survey of individuals with T1DM who chose to fast, it was observed that the majority of the patients experienced episodes of hypoglycemia with different durations and severities. [12]In this regard, the substantial benefits latest diabetes-control technology can confer should not be underestimated. It is demonstrated that in patients with type 1 diabetes who fast, continuous subcutaneous insulin infusion (CSII) devices can be markedly more effective in reducing the risk for hypoglycemia in comparison with the traditional insulin injection regimens. [13] Moreover, during the recent years, the advent of the low-glucose suspend (LGS) feature for insulin pumps has proved to be of great benefit in reducing the episodes of hypoglycemia, and helped fasting patients with type 1 diabetes to perform the ritual in a safer manner [14].

People with T1DM who choose to fast should regularly check their blood glucose levels, ideally using a continuous glucose monitoring (CGM) device. Findings of a recent study has provided credible evidence indicating that real-time CGM is significantly advantageous over the conventional blood sugar monitoring methods in terms of improvement of several adverse diabetes outcomes including reducing $\mathrm{HbAlc}$, minimizing blood glucose fluctuations, decreasing the risk of hypoglycemia, and increasing the Time in Range (TIR) (which is defined as the time spent in the target range of plasma glucose between 70 and $180 \mathrm{mg} /$ dL). [15] However, it should be mentioned that in children and adolescents with T1DM, the effectiveness of CGM depends on the compliance of the patients and duration of the sensor use during fasting hours. [16] Besides improvement of glycemic control, in Ramadan Fasting, the use of technologically-advanced diabetes control technologies is demonstrated to be of great benefit in prediction of hypoglycemia and glycemic excursions. [17-19] Several studies have highlighted the advantages of other advanced technologies such as flash glucose monitoring (FGM) systems in fasting patients with T1DM [20].

In some Islamic cultures, food and beverage consumed during Ramadan is traditionally high in fat and carbohydrates, and patients with T1DM should be warned against the grave consequences. [21] Besides, drinking large amounts of water and liquids before dawn should be discouraged, and instead, moderate and continuous consumption of water and beverages during non-fasting hours should be promoted [22].

In terms of insulin therapy for management of patients with type 1 diabetes who fast in Ramadan, several guidelines recommend that pre-prandial bolus insulin is advantageous over the insulin administered during or after Sahar and Iftar. They also recommend that frequent self-monitoring of blood sugar (SMBG), or ideally continuous glucose monitoring (CGM), should provide the basis for proper adjustment of insulin doses. [23] In this regard, several studies recommend that administration of a long-acting insulin analogue in conjunction with a premeal dose of rapid-acting insulin analogue should be advocated as this approach is demonstrated to be associated with a lower risk of hypoglycemia, particularly in children and adolescents [24].

In most observational studies, the safety and efficacy of first-generation basal insulin analogues (such as glargine) in fasting individuals with controlled T1DM have been documented. [25] Nonetheless, in a few studies, it has been observed that this regimen may lead to significant decline in 
plasma glucose concentrations with a tendency towards hypoglycemia, which often occurs close to the end of the fasting hours. [26] To minimize this risk, some authors have suggested that the basal insulin dose should be reduced in Ramadan. [27] Most authors have recommended that the pre-Ramadan basal dose should be reduced by $20 \%$ and given earlier in the evening, although some have proposed a reduction of up to $40 \%$ [28].

Basal insulin should, ideally, be administered earlier in the day. This is of great importance for reducing the exposure of the body organs and tissues to active insulin in circulation during the last hours of fasting. This approach is confirmed by several studies which have used continuous glucose monitoring devices, and most of them have demonstrated that approximately $70 \%$ of the hypoglycemic events occurs in the last $6 \mathrm{~h}$ of fasting. [29] Nonetheless, there is no consensus about the precise necessary adjustments to insulin doses during Ramadan for favorable glycemic control without the risk of hyperglycemia. In this regard, Alalwan et al. have proposed administration of a pre-Iftar dose equal to that of a pre-Ramadan lunch dose and a pre-dawn dose equal to a usual pre-Ramadan evening dose of rapid acting insulin. [30] Similarly, the precise timing of the doses remains controversial. One study has demonstrated that administration of a bolus dose of rapid-acting insulin $20 \mathrm{~min}$ before a meal results in a significantly better postprandial glucose control than when the insulin bolus is given just before meals or immediately after them. This timing is particularly very important when high-fat and high-protein meals are ingested, which usually occurs in Iftar [31].

As regards the type of insulin, particularly in children and adolescents, it has been shown that the use of long acting insulin analogues are preferable over intermediate acting insulins as the latter leads to a steady fall in blood glucose levels in the last hours of fasting prior to the iftar meal. [32] It should be mentioned here, that insulin pumps have proved to be impressively effective in management of patients with type 1 diabetes who fast during Ramadan. Adjustments of an insulin pump can greatly facilitate reducing the risks of both hypoglycemia caused by prolonged daytime starvation and hyperglycemia due to excessive iftar meal, as compared with the conventional regimen of several insulin injections. The ability to lower the basal insulin infusion rate or even suspending it by insulin pumps can enable persons with diabetes to fast safer and minimize the risk of hypoglycemic bouts during fasting hours [27].

\section{Management of patients with type 2 diabetes}

There is universal consensus that most patients with type 2 diabetes mellitus (T2DM) may fast during Ramadan without any major concern. Nonetheless, similar to patients with type 1 diabetes, patients with type 2 diabetes may be confronted with several challenges associated with the fastingfeasting nature of the ritual and the metabolic consequences. More specifically, wide fluctuations in blood glucose levels can lead to severe hyperglycemia and hypoglycemia, and their associated risks.

Prior to Ramadan, clinicians should perform a comprehensive evaluation and assessment for all patients with type 2 diabetes who intend to fast during Ramadan, and consider individualized approaches for their patients. In these pre-Ramadan visits, all patients need to be provided with detailed guidance on all related aspects such as nutrition, proper hydration, physical activity and exercise, and selfmonitoring of blood sugar. Most importantly, they should receive clear guidance about the symptoms of potential critical situations, and be advised about how to break the fast in such situations. They should also be required to measure their blood glucose levels more frequently and vigilantly during Ramadan, and the advantages of the use of continuous glucose monitoring (CGM) or flash glucose monitoring (FGM) systems need to be mentioned to them, so that they procure and use them if affordable.

The type, dose, and timing of the anti-diabetic medications each patient takes is immensely influential in the management potential risks involved in their use, but most antidiabetic agents used for treatment of type 2 diabetes are generally considered safe. It should be mentioned, however, that in patients who take several glucose lowering medications, the risk of hypoglycemia may be amplified. [33] Particularly, in patients who take a basal insulin in combination with a DPP4I, metformin, or other glucose lowering agents, the risk of hypoglycemia can greatly increase [34].

Severe complications in fasting individuals who take metformin are quite uncommon, and generally, fasting people with T2DM may continue its consumption without any concern. Similar to Metformin, Acarbose can be safely prescribed to fasting patients with type 2 diabetes. Likewise, despite scarcity of research on using Thiazolidinediones in Ramadan, hitherto, no concern has been raised regarding their prescription to type 2 diabetes patients who fast. Nonetheless, one study on 86 fasting type 2 diabetic patients demonstrated that their consumption may lead to weight gain. [35] Moreover, it should be noted to patients with diabetes that they should not start taking Thiazolidinediones in Ramadan, and this class of glucose-lowering agents should be taken with iftar and not Sahar.

Short-acting insulin secretagogues (such as repaglinide and nateglinide) act through stimulation of pancreatic $\beta$ cells which leads to increased insulin secretion. Results of several studies have provided convincing evidence that this class of antidiabetic medications does not lead to hypoglycemia bouts, and its use in Ramadan Fasting is quite safe. [36-38]. Similarly, use of Glucagon-like peptide-1 receptor agonists 
(GLP-1 RAs) is associated with minimal risk of hypoglycemic attacks in Ramadan Fasting when used alone, but there are some risks involved in their use if they are prescribed in combination with other antidiabetic medications (such as insulin or sulfonylureas). [39] As regards Dipeptidyl peptidase-4 (DPP-4) inhibitors, similar to the previous classes of antidiabetics mentioned, several studies have demonstrated that the risks involved in taking this class of medications during Ramadan Fasting is considerably low [40].

As Sulphonylureas (SUs) SUs stimulate pancreatic $\beta$ cells to produce more insulin, traditionally, many clinicians are concerned that this class of antidiabetics may impose some degree of hypoglycemia risk during Ramadan Fasting. [41] Nonetheless, several studies have demonstrated that people with T2DM who fast in Ramadan may continue using newer SUs such as gliclazide, gliclazide and glimepride without any concern, [38] but older drugs of this class, (such as, glibenclamide) should definitely be discontinued in Ramadan [40].

Notwithstanding the fact that Sodium-glucose cotransporter-2 (SGLT2) inhibitors (such as dapagliflozin, canagliflozin, empagliflozin and ertugliflozin) are generally believed to be safe in people with T2DM who fast during Ramadan, some studies have concluded that the risk of dehydration may be increased by their use in fasting patients who are particularly vulnerable in this regard. As a result, several guidelines have prohibited their prescription in individuals with frequent vomiting, diarrhea, or intake of ACE-I and diuretics [42].

It is widely believed that type 2 diabetes patients who take insulin during Ramadan are at greater risk for development of hypoglycemia, particularly when insulin is used in complex regimens along with other antidiabetic medications. Nonetheless, findings of several studies have demonstrated that insulin would be tolerated well provided that the conventional twice daily premixed or intermediate-acting dose would be changed to one dose of long-acting or intermediate-acting insulin in the evening, and two doses of rapidacting insulin with Shar and Iftar. [27] Findings of some studies have suggested that total substitution of insulin by insulin analogues may reduce the risk of hypoglycemia in people with T2DM who fast during Ramadan. [43, 44] It should be mentioned, however, that fasting patients with type 2 diabetes who wish switch to insulin analogues for the month of Ramadan need to begin with a starting dose of $20-30 \%$ lower compared to the regular insulin dose [45].

Basal insulin is generally considered safe in Ramadan Fasting. Authors of one study in a group of fasting patients with T2DM who were taking insulin glargine and glimepiride have observed and reported only mild hypoglycemic events. [46] Authors of another study have contended that the second-generation basal insulin analogue, glargine, may be safely used in Ramadan Fasting in combination with other oral antidiabetic medications. [47] It should be noted, moreover, that in addition to long-acting basal insulin, injection of rapid or short-acting insulins may be necessary for proper management of post-prandial hyperglycemia episodes. [44] As they require fewer injections in comparison with the regimens requiring basal-bolus injection, premixed insulins which contain both short- and intermediate-acting insulins can be advantageous in management of fasting patients with type 2 diabetes. Nonetheless, some authors have raised concerns that their use may be associated with a higher risk of hypoglycemia [48].

\section{Considerations in pregnant women with diabetes}

Regardless of religious fatwas and decrees in different countries and various branches of Islam, every year, many pregnant Muslims choose to fast in Ramadan. [49, 50] Therefore, all clinicians who visit fasting patients need to familiarize themselves with the principles of the management of fasting pregnant women with diabetes so as to minimize the risks associated.

Different studies have published contradictory conclusions on the subject of healthy pregnancy and Ramadan Fasting. Whilst Some studies have concluded that healthy non-diabetic pregnant women may fast without any threat to either the mother or the fetus, [51, 52] some authors have reported decreased placental weight in pregnant women who fast as a potential threat (although without affecting the birth weight). [53] Regardless of such controversies in healthy pregnant women, the current general consensus for fasting women with pre-existing T1DM or T2DM is that they are categorized as the high-risk fasting group and should not be allowed to fast during Ramadan [54].

It should not be overlooked, however, that a considerable number of pregnant women do fast during Ramadan, and clinicians should acquaint themselves with the basic knowledge and skills for management of pregnant patients with diabetes who choose to fast against medical advice. Traditionally, many experienced clinicians believe that pregnant women with diabetes should be managed with insulin, metformin, or glibenclamide. Notwithstanding of the safety and efficacy of this approach, in Ramadan Fasting, clinicians should be advised against prescription of glibenclamide to pregnant women $[40,41]$.

\section{Elderly individuals with diabetes}

Although the elderly with diabetes are considered as being at a higher risk for development of the related complications, every year, many senior diabetic individuals observe the ritual [28] In this group of fasting patients, it is of utmost 
importance that diabetes-related comorbidities and complications should be thoroughly evaluated and monitored. In the elderly with diabetes, diabetic kidney disease, cardiovascular disease (CVD), retinopathy, and other complications of diabetes are notoriously common [55] Moreover, elderly patients are at greater risk for dementia, volume depletion, visual impairment, and consequently, they are venerable to falls which may lead to hip fracture [56-58] Therefore, fasting individuals in advanced ages should be prescribed antidiabetic medications with minimal risks for development of hypoglycemia which may lead to falls and fractures. Besides, this group of patients should be informed of the critical importance of regular self-monitoring of blood glucose levels.

\section{Diabetes complications and ramadan fasting}

There is universal concern that people with diabetes microvascular and macrovascular complications who fast during Ramadan may impose an exaggerated risk of exacerbation of them on themselves. [28] It is documented that diabetes per se is a great risk for development of cardiovascular disease (CVD), and the rate of stroke is significantly increased in diabetic patients. [59] Therefore, some unhealthy practices associated with the ritual in some cultures (such as binge intake of high amounts of carbohydrates and fats in Iftar and Sahar meals) can amplify the risk of CVD or stroke in Ramadan. [60] Nevertheless, fasting can be beneficial in this regard if practiced responsibly as favorable and tight glycemic control during Ramadan can effectively mitigate the risk for cardiovascular incidents and stroke [61].

Patients with diabetes are at a higher risk for development of different kidney-related complications. [62, 63] It is demonstrated that fasting diabetic patients with CKD are more apt to have high levels of urinary NAG ( $\mathrm{N}$-acetyl- $\beta$-D-glucosaminidase which is a marker of renal tubulopathy) in comparison with healthy fasting individuals, and this high level is closely correlated with blood glucose levels. [64] In one study, Mbarki et al. observed that in diabetic patients with CKD who fasted renal function was deteriorated. [65] Similarly, other authors have concluded that more sever adverse renal outcomes are common in fasting patients with higher stages of CKD during Ramadan. [66] Interestingly, it is even contended that the risk for development of CVD is significantly increased in diabetic patients with CKD who fast during Ramadan. [67] Notwithstanding such findings, a meta-analysis carried out on the mean differences of the eGFR before and after Ramadan has concluded that there existed no significant difference (mean difference 0; 95\% CI -0.19-0.19). [68] But regardless of contradictory findings about Ramadan fasting in diabetic patients with $\mathrm{CKD}$, in most guidelines, it is recommended that those with stable renal function may fast, and temporary changes are believed to fade away after Ramadan [69].

\section{Conclusion}

In management of patients with diabetes in Ramadan, education and risk assessment should be given priority over any clinical decision-making or intervention. Accordingly, different risk groups should receive their personal Ramadan-specific diabetes management plans. It should be taken into consideration by all clinicians and general practitioners that Ramadan Fasting can make great alternations to the levels of different hormones, and this may adversely (or favorably) affect the health of patients living with diabetes. On the other hand, there are several physical and spiritual health benefits to patients with diabetes which are conferred through Ramadan Fasting. Therefore, it is imperative that people with diabetes consult with their clinicians prior to commencement of Ramadan Fasting on an annual basis.

\section{Declarations}

Conflict of interests The authors declare none

\section{References}

1. IDF Diabetes Atlas. International Diabetes Federation Brussels, Belgium; (2019).

2. Ghani F. Most Muslims say they fast during Ramadan. (2013).

3. Ahmad S, Shukla AK, Shrama S, Pant B, Tripathi MK. Effects of Ramadan Fasting on Social, Psychological and Physical Well Being to Health. International Journal of Contemporary Microbiology. 2015;1(2):25-9.

4. Salti I, Bénard E, Detournay B, Bianchi-Biscay M, Le Brigand C, Voinet C, et al. A population-based study of diabetes and its characteristics during the fasting month of Ramadan in 13 countries: results of the epidemiology of diabetes and Ramadan 1422/2001 (EPIDIAR) study. Diabetes Care. 2004;27(10):2306-11.

5. Hassanein M, Abdelgadir E, Bashier A, Rashid F, Al Saeed M, Khalifa A, et al. The role of optimum diabetes care in form of Ramadan focused diabetes education, flash glucose monitoring system and pre-Ramadan dose adjustments in the safety of Ramadan fasting in high risk patients with diabetes. Diabetes Res Clin Pract. 2019;150:288-95.

6. Tourkmani AM, Alharbi TJ, Rsheed AMB, AlRasheed AN, AlBattal SM, Abdelhay O, et al. Impact of Ramadan Focused Education Program on medications adjustment for patients with type 2 diabetes in a primary health care institution in Saudi Arabia. Diabetes Metab Syndr. 2019;13(1):161-5.

7. Benaji B, Mounib N, Roky R, Aadil N, Houti I, Moussamih S, et al. Diabetes and Ramadan: review of the literature. Diabetes Res Clin Pract. 2006;73(2):117-25.

8. Bravis V, Hui E, Salih S, Mehar S, Hassanein M, Devendra D. Ramadan Education and Awareness in Diabetes (READ) programme for Muslims with Type 2 diabetes who fast during Ramadan. Diabet Med. 2010;27(3):327-31.

9. Haghdoost A, Poorranjbar M. The interaction between physical activity and fasting on the serum lipid profile during Ramadan. (2009).

10. Ann W. Recognizing \& Treating Hypoglycemia, Hyperglycemia \& Other Diabetes-related Health Problems. 
11. UK D. Hypos and hypers. (2017).

12. Hassanein M, Alamoudi RM, Kallash M-A, Aljohani NJ, Alfadhli EM, El Tony $\mathrm{L}$, et al. Ramadan fasting in people with type 1 diabetes during COVID-19 pandemic: The DaR Global survey. diabetes research and clinical practice. (2021);172:108626.

13. Loh HH, Lim LL, Loh HS, Yee A. Safety of Ramadan fasting in young patients with type 1 diabetes: A systematic review and meta-analysis. Journal of diabetes investigation. 2019;10(6):1490-501.

14. Bin-Abbas BS. Insulin pump therapy during Ramadan fasting in type 1 diabetic adolescents. Ann Saudi Med. 2008;28(4):305-6.

15. Cameron FJ, Amin R, De Beaufort C, Codner E, Acerini CL. Diabetes in adolescence Pediatric diabetes. 2014;15:245-56.

16. Miller VA, Xiao R, Slick N, Feudtner C, Willi SM. Youth Involvement in the Decision to Start CGM Predicts Subsequent CGM Use. Diabetes Care. 2020;43(10):2355-61.

17. Bonakdaran S, Khajeh-Dalouie M. The effects of fasting during Ramadan on glycemic excursions detected by continuous glucose monitoring system (CGMS) in patients with type 2 diabetes. Med J Malaysia. 2011;66(5):447-50.

18. Lessan N, Hannoun Z, Hasan H, Barakat M. Glucose excursions and glycaemic control during Ramadan fasting in diabetic patients: insights from continuous glucose monitoring (CGM). Diabetes Metab. 2015;41(1):28-36.

19. Kaplan W, Afandi B, Al Hassani N, Hadi S, Zoubeidi T. Comparison of continuous glucose monitoring in adolescents with type 1 diabetes: Ramadan versus non-Ramadan. Diabetes Res Clin Pract. 2017;134:178-82.

20. Afandi B, Kaplan W, Majd L, Roubi S. Rate, timing, and severity of hypoglycemia in adolescents with type 1 diabetes during Ramadan fasting: a study with freestyle libre flash glucose monitoring system. Ibnosina Journal of Medicine and Biomedical Sciences. 2018;10(1):9.

21. Eltoum N, Washi S, Al Twaim A. Dietary habits and nutrients intake of diabetic adolescents during Ramadan fasting. International Journal of Food, Nutrition and Public Health. (2014);7(1).

22. Deeb A, Elbarbary N, Smart CE, Beshyah SA, Habeb A, Kalra S, et al. ISPAD Clinical Practice Consensus Guidelines: Fasting during Ramadan by young people with diabetes. Pediatr Diabetes. 2020;21(1):5-17.

23. Bell KJ, Smart CE, Steil GM, Brand-Miller JC, King B, Wolpert HA. Impact of fat, protein, and glycemic index on postprandial glucose control in type 1 diabetes: implications for intensive diabetes management in the continuous glucose monitoring era. Diabetes Care. 2015;38(6):1008-15.

24. Ibrahim M, Al Magd MA, Annabi FA, Assaad-Khalil S, Ba-Essa EM, Fahdil I, et al. Recommendations for management of diabetes during Ramadan: update 2015. BMJ Open Diabetes Res Care. 2015;3(1):e000108.

25. Al-Khawari M, Al-Ruwayeh A, Al-Doub K, Allgrove J. Adolescents on basal-bolus insulin can fast during Ramadan. Pediatr Diabetes. 2010;11(2):96-100.

26. Danne T, Bangstad HJ, Deeb L, Jarosz-Chobot P, Mungaie L, Saboo B, et al. Insulin treatment in children and adolescents with diabetes. Pediatr Diabetes. 2014;15(S20):115-34.

27. Al-Arouj M, Assaad-Khalil S, Buse J, Fahdil I, Fahmy M, Hafez $\mathrm{S}$, et al. Recommendations for management of diabetes during Ramadan: update 2010. Diabetes Care. 2010;33(8):1895-902.

28. Hassanein M, Al-Arouj M, Hamdy O, Bebakar WMW, Jabbar A, Al-Madani A, et al. Diabetes and Ramadan: practical guidelines. Diabetes Res Clin Pract. 2017;126:303-16.

29. Afandi B, Kaplan W, Al Hassani N, Hadi S, Mohamed A. Correlation between pre-ramadan glycemic control and subsequent glucose fluctuation during fasting in adolescents with Type 1 diabetes. J Endocrinol Invest. 2017;40(7):741-4.
30. AlAlwan I, Al BA. effects of Ramadan fasting on children with type 1 diabetes. International Journal of Diabetes Mellitus. 2010;2(2):127-9.

31. Smart CE, King BR, Lopez PE. Insulin dosing for fat and protein: is it time? Diabetes Care. 2020;43(1):13-5.

32. Beshyah SA. Fasting during the month of Ramadan for people with diabetes: medicine and Fiqh united at last. Ibnosina J Med Biomed Sci. 2009;1(2):58-60.

33. Jabbar A, Hassanein M, Beshyah SA, Boye KS, Yu M, Babineaux SM. CREED study: Hypoglycaemia during Ramadan in individuals with Type 2 diabetes mellitus from three continents. Diabetes Res Clin Pract. 2017;132:19-26.

34. Elhadd T, Dabbous Z, Bashir M, Elzouki A, Ghadban W, Baagar $\mathrm{K}$, et al. Incidence of hypoglycaemia in patients with type-2 diabetes taking multiple glucose lowering therapies during Ramadan: the PROFAST Ramadan Study. J Diabetes Metab Disord. 2018;17(2):309-14.

35. Vasan S, Thomas N, Bharani AM, Abraham S, Job V, John B, et al. A double-blind, randomized, multicenter study evaluating the effects of pioglitazone in fasting Muslim subjects during Ramadan. Int J Diabetes Dev Ctries. 2006;26(June):70-6.

36. Cesur M, Corapcioglu D, Gursoy A, Gonen S, Ozduman M, Emral $\mathrm{R}$, et al. A comparison of glycemic effects of glimepiride, repaglinide, and insulin glargine in type 2 diabetes mellitus during Ramadan fasting. Diabetes Res Clin Pract. 2007;75(2):141-7.

37. Anwar A, Azmi KN, Hamidon B, Khalid B. An open label comparative study of glimepiride versus repaglinide in type 2 diabetes mellitus Muslim subjects during the month of Ramadan. Med J Malaysia. 2006;61(1):28-35.

38. Mafauzy M. Repaglinide versus glibenclamide treatment of Type 2 diabetes during Ramadan fasting. Diabetes Res Clin Pract. 2002;58(1):45-53.

39. Amori RE, Lau J, Pittas AG. Efficacy and safety of incretin therapy in type 2 diabetes: systematic review and meta-analysis. JAMA. 2007;298(2):194-206.

40. Al Sifri S, Basiounny A, Echtay A, Al Omari M, Harman-Boehm I, Kaddaha G, et al. The incidence of hypoglycaemia in Muslim patients with type 2 diabetes treated with sitagliptin or a sulphonylurea during Ramadan: a randomised trial. Int J Clin Pract. 2011;65(11):1132-40.

41. Aravind S, Tayeb KA, Ismail SB, Shehadeh N, Kaddaha G, Liu R, et al. Hypoglycaemia in sulphonylurea-treated subjects with type 2 diabetes undergoing Ramadan fasting: a five-country observational study. Curr Med Res Opin. 2011;27(6):1237-42.

42. Bajaj HS, Abouhassan T, Ahsan MR, Arnaout A, Hassanein M, Houlden RL, et al. Diabetes Canada position statement for people with types 1 and 2 diabetes who fast during Ramadan. Can J Diabetes. 2019;43(1):3-12.

43. Grunberger G. Insulin analogs — are they worth it? Yes! Diabetes Care. 2014;37(6):1767-70.

44. Akram J, De Verga V, Group TRS. Insulin lispro (Lys (B28), Pro (B29)) in the treatment of diabetes during the fasting month of Ramadan. Diabet Med. 1999;16(10):867-74.

45. Hassanein M, Belhadj M, Abdallah K, Bhattacharya AD, Singh AK, Tayeb K, et al. Management of Type 2 diabetes in Ramadan: Low-ratio premix insulin working group practical advice. Indian journal of endocrinology and metabolism. 2014;18(6):794.

46. Salti I, Diabetes, Group RS. Efficacy and safety of insulin glargine and glimepiride in subjects with Type 2 diabetes before, during and after the period of fasting in Ramadan. Diabetic medicine. (2009);26(12):1255-61.

47. Hassanein M, Buyukbese MA, Malek R, Pilorget V, Naqvi M, Berthou B, et al. Real-world safety and effectiveness of insulin glargine $300 \mathrm{U} / \mathrm{mL}$ in participants with type 2 diabetes who fast 
during Ramadan: the observational ORION study. Diabetes Res Clin Pract. 2020;166:108189.

48. Bellido V, Suarez L, Rodriguez MG, Sanchez C, Dieguez M, Riestra M, et al. Comparison of basal-bolus and premixed insulin regimens in hospitalized patients with type 2 diabetes. Diabetes Care. 2015;38(12):2211-6.

49. Firouzbakht M, Kiapour A, Jamali B, Kazeminavaei F, Taghlilin F, Gorji AMH. Fasting in pregnancy: A survey of beliefs and manners of Muslim women about Ramadan fasting. Annals of Tropical Medicine and Public Health. 2013;6(5):536.

50. Robinson T, Raisler J. Each one is a doctor for herself": Ramadan fasting among pregnant Muslim women in the United States. Ethn Dis. 2005;15(1 Suppl 1):S1-99.

51. Dikensoy E, Balat O, Cebesoy B, Ozkur A, Cicek H, Can G. Effect of fasting during Ramadan on fetal development and maternal health. Journal of Obstetrics and Gynaecology Research. 2008;34(4):494-8.

52. Dikensoy E, Balat O, Cebesoy B, Ozkur A, Cicek H, Can G. The effect of Ramadan fasting on maternal serum lipids, cortisol levels and fetal development. Arch Gynecol Obstet. 2009;279(2):119-23.

53. Alwasel S, Abotalib Z, Aljarallah J, Osmond C, Alkharaz S, Alhazza I, et al. Secular increase in placental weight in Saudi Arabia. Placenta. 2011;32(5):391-4.

54. Afandi BO, Beshyah SA, Hassanein MM, Jabbar A, Khalil AB. The individualization of care for people with diabetes during Ramadan fasting: A narrative review. Ibnosina Journal of Medicine and Biomedical Sciences. 2020;12(2):98.

55. Kirkman MS, Briscoe VJ, Clark N, Florez H, Haas LB, Halter JB, et al. Diabetes in older adults. Diabetes Care. 2012;35(12):2650-64.

56. van Dijk PT, Meulenberg OG, Van de Sande HJ, Habbema JDF. Falls in dementia patients. Gerontologist. 1993;33(2):200-4.

57. Irfannuddin I, Santoso B, Zein RH, Naufal AF, editors. The Effect of Aerobic Exercise and Caloric Restriction on Mice's Brain Tissue PGC- $1 \alpha$ Levels and Their Memory Abilities. Journal of Physics: Conference Series; (2019): IOP Publishing.

58. Laatar R, Borji R, Baccouch R, Zahaf F, Rebai H, Sahli S. Effects of Ramadan fasting on postural balance and attentional capacities in elderly people. J Nutr Health Aging. 2016;20(5):553-60.

59. Aronson D, Edelman ER. Coronary artery disease and diabetes mellitus. Cardiol Clin. 2014;32(3):439-55.

60. Sassi M, Chakroun T, Chouchène S, Hellara I, Boubaker H, Grissa $\mathrm{MH}$, et al. Does Lipid Profile Affect Thrombin Generation During
Ramadan Fasting in Patients With Cardiovascular Risks? Clin Appl Thromb Hemost. 2017;23(8):980-6.

61. Group UKPDS. A 6-year, randomized, controlled trial comparing sulfonylurea, insulin, and metformin therapy in patients with newly diagnosed type 2 diabetes that could not be controlled with diet therapy (UKPDS 24). Ann Intern Med. (1998);128:165-75.

62. Hassanien AA, Al-Shaikh F, Vamos EP, Yadegarfar G, Majeed A. Epidemiology of end-stage renal disease in the countries of the Gulf Cooperation Council: a systematic review. JRSM short reports. 2012;3(6):1-21.

63. Levey AS, Coresh J, Balk E, Kausz AT, Levin A, Steffes MW, et al. National Kidney Foundation practice guidelines for chronic kidney disease: evaluation, classification, and stratification. Ann Intern Med. 2003;139(2):137-47.

64. El-Wakil HS, Desoky I, Lotfy N, Adam AG. Fasting the month of Ramadan by Muslims: could it be injurious to their kidneys? Saudi Journal of Kidney Diseases and Transplantation. 2007;18(3):349.

65. Mbarki H, Tazi N, Najdi A, Tachfouti N, Arrayhani M, Sqalli T. Effects of fasting during Ramadan on renal function of patients with chronic kidney disease. Saudi Journal of Kidney Diseases and Transplantation. 2015;26(2):320.

66. Bakhit AA, Kurdi AM, Wadera JJ, Alsuwaida AO. Effects of Ramadan fasting on moderate to severe chronic kidney disease: a prospective observational study. Saudi Med J. 2017;38(1):48.

67. NasrAllah MM, Osman NA. Fasting during the month of Ramadan among patients with chronic kidney disease: renal and cardiovascular outcomes. Clin Kidney J. 2014;7(4):348-53.

68. Bragazzi NL. Ramadan fasting and chronic kidney disease: does estimated glomerular filtration rate change after and before Ramadan? Insights from a mini meta-analysis. Int J Nephrol Renov Dis. 2015;8:53.

69. Bernieh B, Al Hakim MR, Boobes Y, Zidan FMA. Fasting Ramadan in chronic kidney disease patients: clinical and biochemical effects. Saudi Journal of Kidney Diseases and Transplantation. 2010;21(5):898.

Publisher's note Springer Nature remains neutral with regard to jurisdictional claims in published maps and institutional affiliations. 